$\begin{array}{llllllllllllll}\text { A C T A C H E M I C A } & \text { S C A N D I N A V I C A } & 16 & \text { (1962) } & 689-694\end{array}$

\title{
On the Solubility of Carbon Dioxide in Molten Halides
}

\author{
Preliminary communication
}

\author{
K. GR JOTHEIM, P. HEGGELUND, C. KROHN and K. MOTZFELDT
}

Institute of Inorganic Chemistry, The Technical University of Norway, Trondheim, Norway

\begin{abstract}
Solubilities of $\mathrm{CO}_{2}$ in molten $\mathrm{NaCl}$ and $\mathrm{KCl}$ have been determined for the temperature range $810-950^{\circ} \mathrm{C}$, at 1 atm pressure of $\mathrm{CO}_{2}$. The solubilities $K_{\mathrm{c}}$, expressed as moles $\mathrm{CO}_{2}$ per $\mathrm{ml}$ of solvent (at $1 \mathrm{~atm}$ ) increase with increasing temperature, being in $\mathrm{NaCl} 4.6 \times 10^{-6}$ and $6.0 \times 10^{-6}$, in $\mathrm{KCl} 4.0 \times 10^{-6}$ and $7.0 \times 10^{-6}$, at 850 and $950^{\circ} \mathrm{C}$, respectively. The heats of solution, calculated from the slope of log $K_{\mathrm{c}}$ versus $1 / T$, are 7.1 and $14.8 \mathrm{kcal} / \mathrm{mole}$, in $\mathrm{NaCl}$ and $\mathrm{KCl}$, respectively.
\end{abstract}

\begin{abstract}
A n number of different processes have been proposed to explain the low current yield in the electrolytic aluminium process. One of the suggested explanations is that the $\mathrm{CO}_{2}$ formed on the anode reacts with dissolved $\mathrm{Al}$ metal or monovalent $\mathrm{Al}^{+}$ions in the molten electrolyte, to form $\mathrm{Al}^{3+}$ ions and CO. It is thus assumed that the dissolved metal or monovalent ion, originating at the cathode, is transported upwards by diffusion or convection in the electrolyte, to the vicinity of the anode where it reacts with the $\mathrm{CO}_{2}$ which is present essentially as gas bubbles.

An alternative explanation suggested here is that the $\mathrm{CO}_{2}$ formed on the anode dissolves to some extent in the melt, where it may react with the dissolved $\mathrm{Al}$ or $\mathrm{Al}^{+}$ion, or possibly it may be transported downwards in the electrolyte by convection and diffusion and oxidize the $\mathrm{Al}$ metal surface. One should be able to support or reject this latter hypothesis by measuring the solubility of $\mathrm{CO}_{2}$ in molten cryolite and cryolite-alumina mixtures. In addition, one would gain some fundamental knowledge of the mechanism of $\mathrm{CO}_{2}$-solution in such melts.

Gas solubilities in molten salts is a rather new field of interest, and most of the work done has been connected with nuclear reactor technology. Grimes et al. ${ }^{1}$ have determined the solubilities for noble gases in $\mathrm{NaF}-\mathrm{ZrF}_{4}$ and $\mathrm{NaF}-$ $\mathrm{ZrF}_{4}-\mathrm{UF}_{4}$ melts. Blander et al. ${ }^{2}$ have measured noble gas solubilities in the $\mathrm{LiF}-\mathrm{NaF}-\mathrm{KF}$ eutectic, while Shaffer et $a .^{3}{ }^{3}$ have investigated the solubilities of $\mathrm{HF}$ in $\mathrm{NaF}-\mathrm{BeF}_{2}$ and $\mathrm{NaF}-\mathrm{ZrF}_{4}$ mixtures. An investigation by Woelk gives some data for Ar solubilities in molten potassium salts. It appears, how-
\end{abstract}

Acta Chem. Scand. 16 (1962) No. 3 


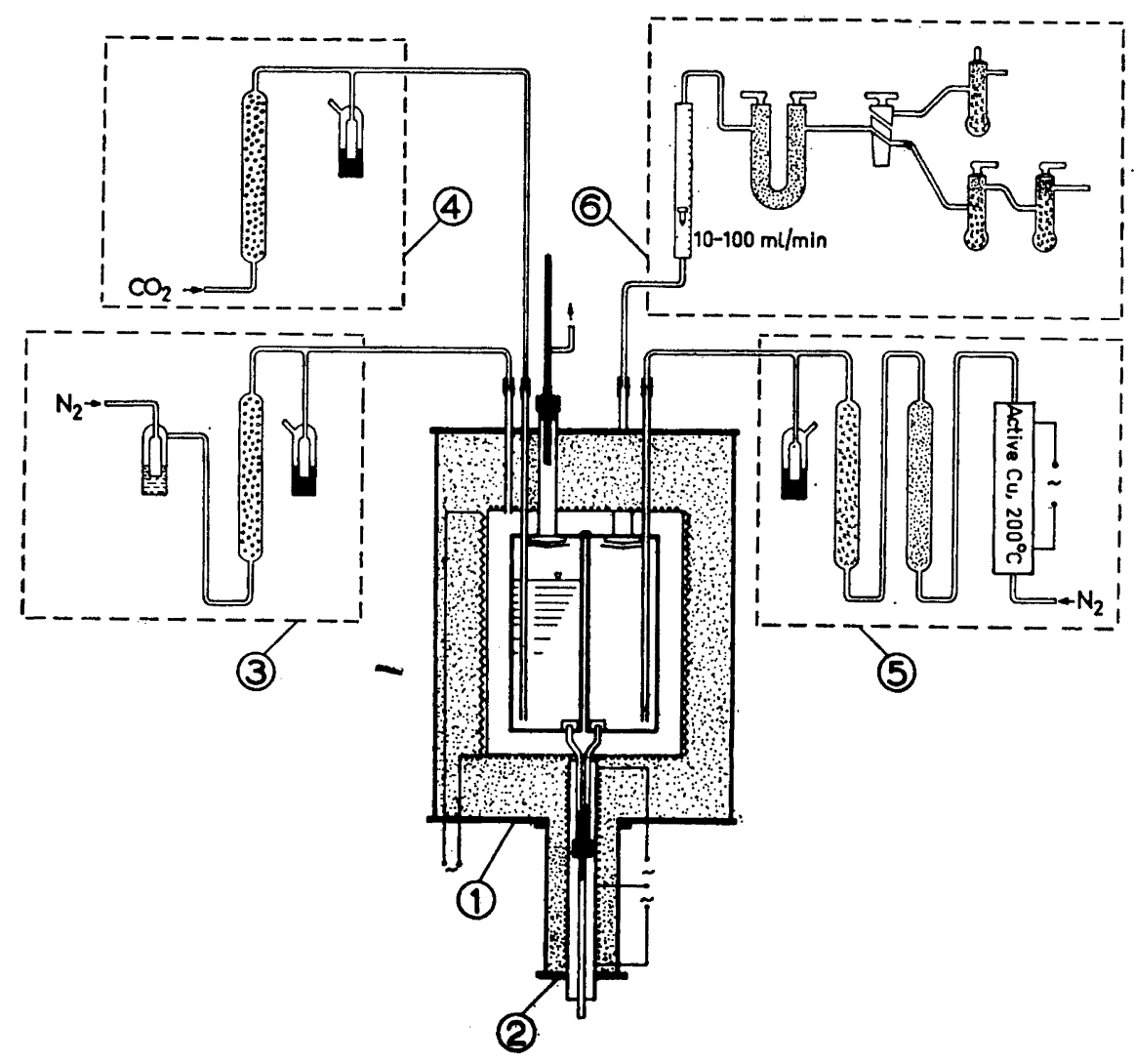

Fig. 1. Diagram of apparatus for measuring solubility of carbon dioxide in molten salt. (1) Furnace with Kanthal A resistors, with nickel vessel consisting of saturating section (left) and stripping section (right) joined by transfer line (bottom). Movable nickel probe shown on top of saturating section. Thermocouple wells not shown. (2) Auxiliary furnace with divided heating element. Top element heated for transfer of melt between nickel sections. Both elements heated for emptying nickel vessel. (3) Drying tube $\left(\mathrm{P}_{\mathrm{a}} \mathrm{O}_{5}\right)$ and safety outlet for protection gas. (4) Same for $\mathrm{CO}_{2}$ saturating gas. (5) Purification train (active $\mathrm{Cu}$, magnesium perchlorate, and Ascarite) for stripping gas. (6) Absorbtion train (magnesium perchlorate $U$ tube, and Ascarite vessels for $\mathrm{CO}_{2}$ absorbtion).

ever, that no data regarding the solubilities of $\mathrm{CO}_{2}$ in molten salts bave been published.

It was decided, then, to investigate the solubility of $\mathrm{CO}_{2}$ in some simpler alkali halides before attempting the cryolite-alumina system.

\section{EXPERIMENTAL}

(a) Apparatus. The method adopted was essentially the same as the one used by Grimes et al. ${ }^{1}$ These authors found the solubilities for HF to be approximately 10 times larger than the corresponding noble gas solubilities. Based on the assumption that the 
Table 1. Solubility of $\mathrm{CO}_{2}$ in molten $\mathrm{NaCl}$ and $\mathrm{KCl}$.

\begin{tabular}{|c|c|c|c|}
\hline \multicolumn{2}{|c|}{$\mathrm{NaCl}$} & \multicolumn{2}{|r|}{$\mathrm{KCl}$} \\
\hline Temp. ${ }^{\circ} \mathrm{C}$ & $\frac{K_{\mathrm{c}} \cdot 10^{6} \text { moles } \mathrm{CO}_{2}}{(\mathrm{ml} \text { solvent. atm })}$ & Temp. ${ }^{\circ} \mathrm{C}$ & $\frac{K_{\mathrm{c}} \cdot 10^{6} \text { moles } \mathrm{CO}_{\mathrm{g}}}{(\mathrm{ml} \text { solvent. atm })}$ \\
\hline $\begin{array}{l}812.2 \\
813.0 \\
829.8 \\
830.4 \\
852.0 \\
903.9 \\
948.3\end{array}$ & $\begin{array}{l}4.20 \\
4.81 \\
4.14 \\
4.18 \\
5.07 \\
5.47 \\
5.71\end{array}$ & $\begin{array}{l}791.0 \\
792.9 \\
802.0 \\
823.5 \\
835.5 \\
863.1 \\
876.4 \\
903.0 \\
925.0 \\
969.9\end{array}$ & $\begin{array}{l}2.73 \\
3.02 \\
2.78 \\
3.76 \\
4.14 \\
5.26 \\
4.02 \\
4.65 \\
6.81 \\
8.90\end{array}$ \\
\hline
\end{tabular}

solubilities for $\mathrm{CO}_{2}$ would be closer to those for $\mathrm{HF}$ than to the solubilities for the noble gases, the present apparatus was designed with a volume approximately $1 / 10$ of the one used by Grimes et al. Also, the saturating and stripping sections were built into a unit, placed in a single furnace. The apparatus thus modified is shown schematically in Fig. 1, together with gas purification train etc.

All sections of the apparatus in contact with the molten salts were made of nickel. The liquid level in the saturating section was determined by means of a movable nickel rod, introduced gas tight and electrically insulated through a packing gland with Teflon gaskets on top of the saturator. The probe was connected in an electric circuit which was completed when the probe made contact with the liquid surface. The relationship between probe position and volume was determined prior to the run by calibration with an aqueous salt solution.

Temperature was measured by Chromel-Alumel thermocouples mounted in thermocouple wells in both saturating and stripping sections. Temperature control was effected by a third thermocouple in the furnace outside the vessel, in connection with a Kent potentiometric controller.

(b) Procedure. Approximately $0.8 \mathrm{~kg}$ of the salt (puriss, from E. Merck) was che rged into the saturating section and heated to temperature. During melting, a frozen seal was established in the transfer tube, thus isolating the salt from the stripping section. After saturating by bubbling $\mathrm{CO}_{2}$ through the melt for $3 \mathrm{~h}$., the frozen seal was destroyed by heating with a small auxiliary furnace, and part of the molten salt was transferred to the stripping section, the exact quantity being determined by means of the nickel probe. The melt thus transferred was stripped of its $\mathrm{CO}_{2}$-content by bubbling pure nitrogen, and the amount of $\mathrm{CO}_{2}$ was determined by absorption in Ascarite ${ }^{5}$.

(c) Results. The results for the solubilities of $\mathrm{CO}_{2}$ in molten $\mathrm{NaCl}$ and $\mathrm{KCl}$, $K_{\mathrm{c}}$, expressed as moles $\mathrm{CO}_{2} \times 10^{-6}$ per ml of solvent (at $1 \mathrm{~atm}$ ), are given in Table 1. In Fig. 2, the values of $\log K_{\mathrm{c}}$ are plotted versus $1 / T$, and a straight line has been fitted to the points for each of the two salts by the method of least squares. It is thus assumed that the heat of solution is constant over the temperature range considered. From the slope of the lines, the heats of solution of $\mathrm{CO}_{2}$ in $\mathrm{NaCl}$ and $\mathrm{KCl}$ are 7.1 and $14.8 \mathrm{kcal} / \mathrm{mole}$, respectively. 


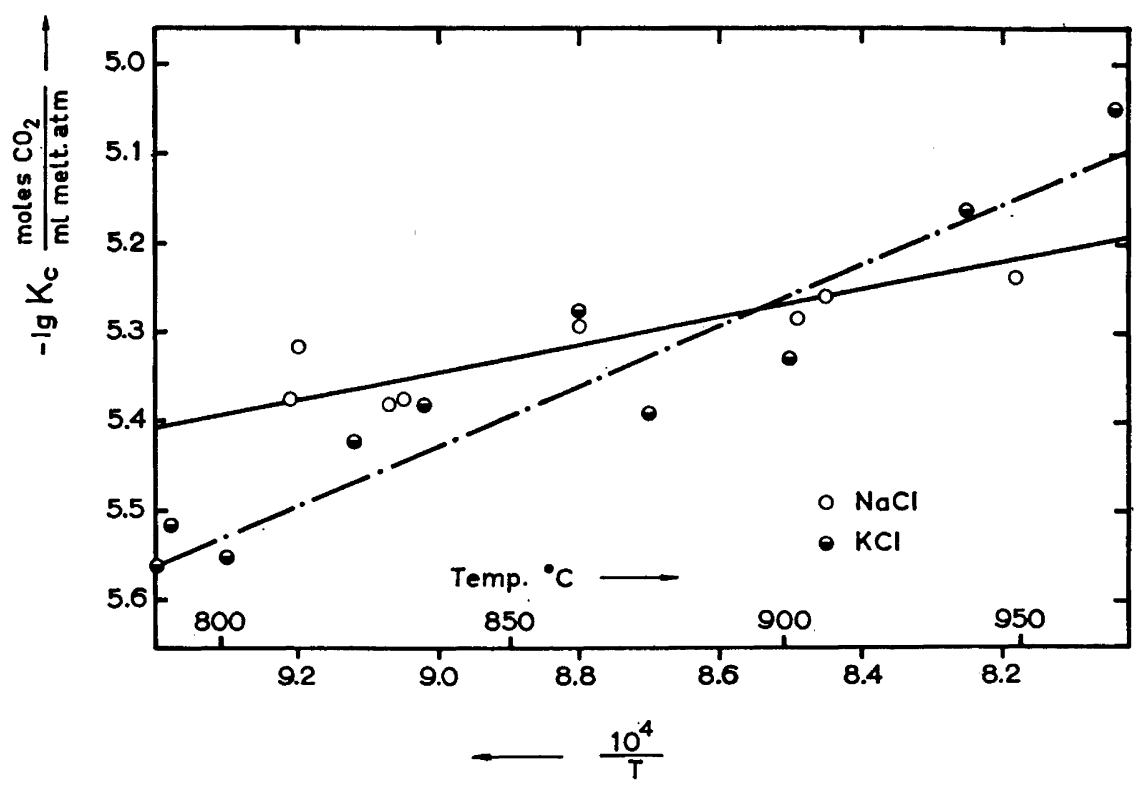

Fig. 2. Solubilities of carbon dioxide in sodium chloride and in potassium chloride melts, plotted as logarithm of solubility versus reciprocal temperature. Straight lines show best fit to experimental points by method of least squares.

\section{DISCUSSION}

(a) Apparatus. Generally one might say that the method applied is well suited for the measurement of $\mathrm{CO}_{2}$-solubilities in molten salts. As can be seen from the fairly large spread in the results, however, there are as yet uncontrolled sources of error.

Preliminary experiments indicated that a saturating time of $3 \mathrm{~h}$ was sufficient. The flow rate for the stripping nitrogen was kept at $70 \mathrm{ml} / \mathrm{min}$. With this rate, from 3 to $10 \mathrm{~h}$ were needed to effect essentially complete stripping, the observed time being roughly proportional to the amount of $\mathrm{CO}_{2}$ dissolved. Assuming that Henry's law holds for the solution, and that each bubble of stripping gas reaches equilibrium with the melt, one may calculate the time necessary to effect $99.9 \%$ complete stripping. The times thus calculated agreed rather well with the observed ones. Hence a shortening of the stripping time can be effected only by increasing the stripping gas flow rate.

Severe trouble was caused by corrosion of the nickel vessel by the molten salt. A detailed discussion of these corrosion problems is published elsewhere ${ }^{6}$, thus only a few remarks will be given here. Intergranular corrosion in the welds led in most cases to complete penetration after $1-2$ weeks of operation. It was then disclosed that, contrary to orders given, the welds had been made with covered electrodes in ordinary atmosphere. This has probably resulted in fairly large amounts of oxygen dissolved in the metal during the welding. 


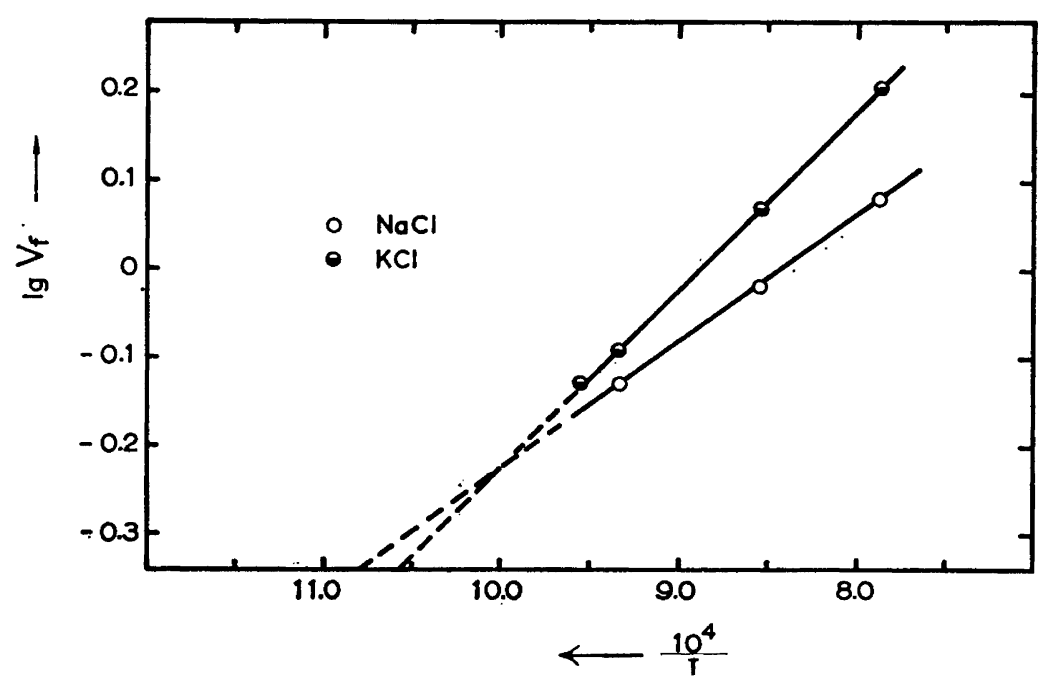

Fig. 3. Logarithm of free volume values for sodium chloride and potassium chloride melts (after Bockris et al. ${ }^{7}$ ) versus reciprocal temperature.

Diffusion of this oxygen to the grain boundaries, combined with the stresses from the periodical melting and solidification of the salt, has then resulted in a type of stress corrosion cracking. In the most recent vessel, made with argon welding following the specifications for reactor systems, this source of trouble apparently has been eliminated.

It is expected that larger values for the solubilities of $\mathrm{CO}_{2}$ will be found when changing to the cryolite-alumina system because of the possible chemical bonding between the carbon dioxide and the oxide in the melt. For this latter system, a volumetric method will be attempted, observing directly the $\mathrm{CO}_{2}$ uptake of the melt.

(b) Interpretation of results. Until additional data are available, it seems unwise to draw too definite conclusions from the results, but a few remarks seem justified. At temperatures just above the melting points, the solubility in $\mathrm{KCl}$ is lower than that in $\mathrm{NaCl}$, but above approximately $900^{\circ} \mathrm{C}$ the situation is reversed, the solubility in $\mathrm{KCl}$ increasing with temperature about twice as fast as in $\mathrm{NaCl}$. One might at first expect these two chlorides to show a more closely similar behaviour than is actually found. But it should be remembered that the two salts show very marked differences also in other respects, such as, e.g., the temperature dependence of their solubilities in water.

It seems plausible to assume that the dissolution process for $\mathrm{CO}_{2}$ in these melts is a purely physical one, with no chemical reaction involved. One would then expect some relation between the $\mathrm{CO}_{2}$ solubility and the free volume in these melts, the solubility being expected to increase with increasing free

Acta Chem. Scand. 16 (1962) No. 3 
volume. Free volume data are available from, e.g., the sonic velocity measurements of Bockris et al. ${ }^{7}$ The free volumes are found to obey the relation

$$
\left(\frac{\partial \ln V_{t}}{\partial(1 / T)}\right)_{P}=-\frac{E^{*}{ }_{h}}{R}
$$

For $\mathrm{NaCl}$ and $\mathrm{KCl}$, the heat of activation, $E^{*}{ }_{\mathrm{h}}$, is essentially constant over the temperature range in question and is found to be $6.6 \mathrm{kcal} / \mathrm{mole}$ for $\mathrm{NaCl}$ and $8.6 \mathrm{kcal} / \mathrm{mole}$ for $\mathrm{KCl}$. A plot of the values of $\log V_{\mathrm{f}}$ found by Bockris et al. versus $1 / T$, gives two crossing lines as shown in Fig. 3, with an appearance rather similar to that of the solubility data in Fig. 2.

A correlation between free volume and solubility is thus found for the two salts investigated so far. Further discussions will have to be deferred until data for the other alkali halides have been obtained.

Acknowledgement. The authors wish to thank The Royal Norwegian Council for Scientific and Industrial Research for financial support in this work.

\section{REFERENCES}

1. Grimes, W. R., Smith, N. V. and Watson, G. M. J. Phys. Chem. 62 (1958) 862.

2. Blander, M., Grimes, W. R., Smith, N. V. and Watson, G. M. J. Phys. Chem. 63 (1959) 1164.

3. Shaffer, J. H., Grimes, W. R. and Watson, G. M. J. Phys. Chem. 63 (1959) 1999.

4. Woelk, H. V. Nukleonik 2 (1960) 278.

5. Hillebrand, W. F. Applied Inorganic Analysis, Wiley, New York 1953, p. 768.

6. Krohn, C. H. Tidsskr. Kjemi, Bergvesen Met. 21 (1961) 183.

7. Bockris, J. O'M. and Richards, N. E. Proc. Roy. Soc. (London) A 241 (1957) 44.

Received October 9, 1961. 